Sheffield, UK

bingportraits@gmail.com

Cite this as: BMJ 2021;372:n775

http://dx.doi.org/10.1136/bmj.n775

Published: 22 March 2021

\title{
The medical establishment is failing the UK public on covid-19
}

\author{
The mainstream medical profession is chronically acquiescent on public health failures
}

\section{Bing Jones former associate specialist in haematology}

In the UK, we are currently bathing in vaccine euphoria, but our remarkable rollout sits on broken public health foundations. The government seems immune to criticism of its overall response to the covid-19 pandemic, and the mainstream medical establishment has failed to stand up to this cynical administration. Barring a few exceptions, public facing senior doctors have failed to counter government narratives and expose the dire weakness of UK public health services.

Vaccination is a massive relief but will not be enough to end this pandemic. Outbreaks will continue and we will need solid public health provision, particularly for deprived populations. It is a fatal folly that we still cannot effectively isolate covid-19 cases, contacts, or travellers. Why does the medical establishment appear to acquiesce to silly, misleading, unscientific policy? The medical establishment appears to shrug off the obscene sums diverted from public service to unsuccessful private initiatives. We have accepted disproportionate death and debt. Now, even with vaccination, we face a bleak future of an unprecedented health backlog, massive financial pressures, and unknown residual levels of infection of covid-19. Independent Sage, The BMJ, and many others warn us endlessly, but the medical mainstream is muted or silent. By remaining silent, it appears to collude with government failures, tolerating schoolboy errors, including our ongoing failure to isolate infection. Royal colleges and other learned institutions fail sufficiently to expose dangerous government policy.

Lockdown is already easing. Vaccination faces potential hurdles: delay, supply, uptake, efficacy, variants. It's unbelievable, therefore, that we still choose not to isolate covid-19 effectively. Testing misses many or most infections, only one in five cases and their contacts isolate effectively, and we do not adequately support those trying to isolate, either financially or practically. We have minimal quarantine for travellers, unsafe schools and workplaces, and we have marginalised local public health services. The health of the nation is probably worse than we dare imagine. I find it inexplicable that the medical establishment is not warning the public every day about our flawed public health provision. I'm amazed that there have been no resignations over unscientific government policy.

I sense a moral as well as an intellectual failure of the medical establishment. The NHS's (mostly Serco’s) €22bn (€26bn; \$31bn) test and trace programme fails to enable outbreak control, and yet it received a further £15bn in the recent budget.

Lateral flow tests and their use in screening pupils is a mockery of scientific process. By contrast, the paltry allocation of funds to enable effective self-isolation ensures poor uptake of testing and consolidates poor compliance with self-isolation. This is reinforced by the marginalisation of local public health teams. Testing, but then failing to isolate, is as fatuous as it is inept. Trust is eroded among marginalised communities. Poor trust, poor testing, and poor vaccine uptake are bedfellows. Failing to collect data on the sources of infection is negligent. Why do senior medical figures not use their platforms to highlight these pervasive, persistent, and pernicious failures?

The BMJ and Independent Sage raise these matters consistently. Yet major failings continue. The relative silence of our profession's official representatives on our fractured public health provision leaves me feeling morally injured. Sadly, we accept that our governments are short term, ideologically driven, commercially influenced-even corrupt. We accept that the media are superficial and influenced by funding. But we expect doctors to be scientific, objective, kind, and focused on long term safe care, particularly for the vulnerable. Doctors know the science and the dangers of prioritising hope over reality. The public rightly expects wisdom. Why aren't senior doctors more vocal on the dangers of poor public health policy and the crippling consequences of lockdown? It's as if public facing doctors feel unable to comment outside their specialties. Are they frightened? Do they feel threatened?

NHS and care staff, vaccine science, and rollout have all been inspiring. But is it not sentimental, even insulting, to laud heroes while ignoring major failures? Is it not an insult to the NHS that Serco's NHS Test and Trace probably fails to reach two thirds of inpatients and their contacts, failing to prevent the next wave of patients? Surely it is the duty of senior doctors to highlight system failures. Is their silence negligent?

Covid-19 is our teacher, giving a heads-up to bigger storms ahead: new epidemics, health backlogs, economic strain, and the health consequences of the climate crisis. These will dwarf our present problems. The medical establishment has lost the courage to expose flawed policy and speak basic public health wisdom. It will cost us dear.

Competing interests: none declared.

Not commissioned, not peer reviewed.

This article is made freely available for use in accordance with BMJ's website terms and conditions for the duration of the covid-19 pandemic or until otherwise determined by BMJ. You may use, download and print the article for any lawful, non-commercial purpose (including text and data mining) provided that all copyright notices and trade marks are retained. 